\title{
INTEGRATING SIMULATION INTO THE RESEARCH AND TEACHING OF CONSTRUCTION ENGINEERING AND MANAGEMENT: REFLECTIONS ON EXPERIENCE
}

\author{
David N. Ford \\ Texas A\&M University \\ College Station, TX 77843-3136, USA
}

\begin{abstract}
Simulations that are used for both research and teaching in Construction Engineering and Management have several common features that provide the foundation for both the synergies between these uses and challenges in their integration. This work uses experiences with 8-10 such integrations as the basis for observations on the practice, a critical assessment of what has worked well and what has not worked well, identification of benefits to both research and teaching, and challenges in integrating simulation for research and teaching. Opportunities for improved combined use of simulation for research and teaching are identified.
\end{abstract}

\section{INTRODCUTION}

Simulation is a useful tool for developing understanding and therefore has great potential for researching and teaching construction engineering and management (CEM) topics. Limited resources by the users of simulation for CEM research and teaching suggests that leveraging applications of simulation for research or for teaching for use in the other domain can improve both effectiveness and efficiency. However, the author's experience suggests that this integration is often incomplete. This paper offers observations, qualitative assessment, and suggestions for the improved integration of simulation into CEM research and teaching.

Simulations for CEM research and teaching almost always have at least four common features. First, a practitioner's problem or challenge motivates the work, specifically by providing a foundation for lessons that students can learn or a knowledge or understanding gap that research may be able to partially fill. Second, the CEM system has a behavior of interest. Examples include the final performance of a contract negotiation, the patterns of progress during a project, and forecasts of completion dates and total expenses. These behaviors are strongly linked to improving the understanding of the practitioner's challenge. Third, there is a structure of an engineered system that generates the behavior of interest. This could be the information available to negotiators, the processes used in a project to make progress, or the resources available and applied. Accurately mapping, describing, and understanding the structure of the system is critical to explaining the behavior of interest (and thereby addressing the challenge). Finally, an artificial environment for learning (whether by students or researchers) that replicates the challenge, behavior, and structure is used in the research or teaching. This is the model that is used to simulate the CEM system. Developing clear images and descriptions of all four common features of simulation for CEM research and teaching is critical to successful integration and use.

The remainder of the paper is structured as follows. A brief description of some of the author's experience with integrating simulation into CEM research and teaching is followed by observations on the practice. This is used to identify potential benefits and challenges of integration for CEM research and for CEM teaching. A description of open issues leads to the closing suggestion that more discussion can lead to improvement. 


\section{SOME EXPERIENCES IN INTEGRATING SIMULATION INTO CEM RESEARCH AND TEACHING}

The author has developed, extended, or used approximately ten different simulations of CEM, with some in multiple formats. The author regularly uses the first group in both teaching and research. Five of them have been developed solely or largely from the author's own work. Two of those five are based on a project simulation model. The Project Management Game has been developed for table-top simulation, web-based use (with minimal success), and stand-alone computer simulation. It is used to teach project dynamics, policy development, project control, and model building. Research has addressed several aspects of projects and their management (Ford and Sterman 1998, 2003a, 2003b). The Tipping Point in Projects simulation extends a portion of the project model to address a single, particularly dangerous and common type of threat to project success (Taylor and Ford 2006,2008). It is only used by computer simulation. The Contingency Management simulation (Ford 2002) was originally a stand-alone computer simulation model but is currently being integrated with the project model for additional research. For teaching it is used primarily as a lecturing aid and to teach modeling. The Project Control simulation has been jointly developed (Ford, Lyneis and Taylor 2007) to investigate control policies and is currently used by the author to teach about Earned Value Management.

The author has also developed the Rig Installation Challenge based on Howell's The Planning Game. Whereas Howell used The Planning Game to investigate and teach about lean construction, the author uses it to teach about risk management, competitive bidding strategies, and professional ethics in CEM. The Rig Installation Challenge was first developed as a table-top simulation and has been recently developed into a computer simulation version. The author has extended the Rig Installation Challenge to research managerial real option (Wu and Ford 2005) and is currently applying the computer simulation for risk management research.

The author has also adapted several simulations that were primarily developed for research by the author or others into CEM teaching tools, including simulations of project resource allocation (Joglekar and Ford 2005; Lee, Ford and Joglekar 2007) that have been used to teach about policy development and model building, Tommeliein's (1998) pipe spools model for teaching model building, Anderson and Parker's (2001) outsourcing model to teach about subcontracting in construction and model building, The Lumber Distribution Game (Sterman 1986, 2000) to teach about supply chains, and the Kaibab Plateau model (Ford and McCormack 2000, Goodman 1974) to teach about policy development. Some of the models used for the simulations described here are available at <https://ceprofs.civil.tamu.edu/dford/>.

\section{OBSERVATIONS ON EXPERIENCE}

Several observations based on the experience with the simulators above can help describe the integration of simulation into CEM research and teaching.

1. Simulation can be only or initially "physical", such as table-top exercises in which students or subjects move symbolic artifacts (e.g. Rig Installation Challenge, Lumber Distribution Game, Project Management Game). Simulations can also be only computer-based (e.g. Contingency Management, Project Control). Simulations can be both physical and computer based.

2. Research by others is fertile ground for the integration of simulation into CEM teaching (e.g. Lumber Distribution Game, Outsourcing, Pipe Spools).

3. Teaching using simulation does not require that students exercise the model in class or at all. In addition to in-class exercises using the simulation simulators can be, and have been by the author, used to teach through multiple other modes, including topic-based lectures, model-based lectures, modeling-based lectures and exercises, out-of-class assignments, term projects, and researchbased lectures. 
4. The focus of CEM research using the simulator does not necessarily need to be about the same topics that the simulator is used for to teach about CEM, or visa versa. Consider the example of the Rig Installation Challenge. The original simulator was altered from the one used to teach about the basics of risk management and decision making to research perceptions of real options in projects. The figure below is part of the research results, showing the difference in the impacts of risk aversion on project performance between rigid and flexible (with a real option) managed projects. The data for this figure was generated using the simulation model and adjusting for the use of a rigid or flexible policy and different risk preferences.

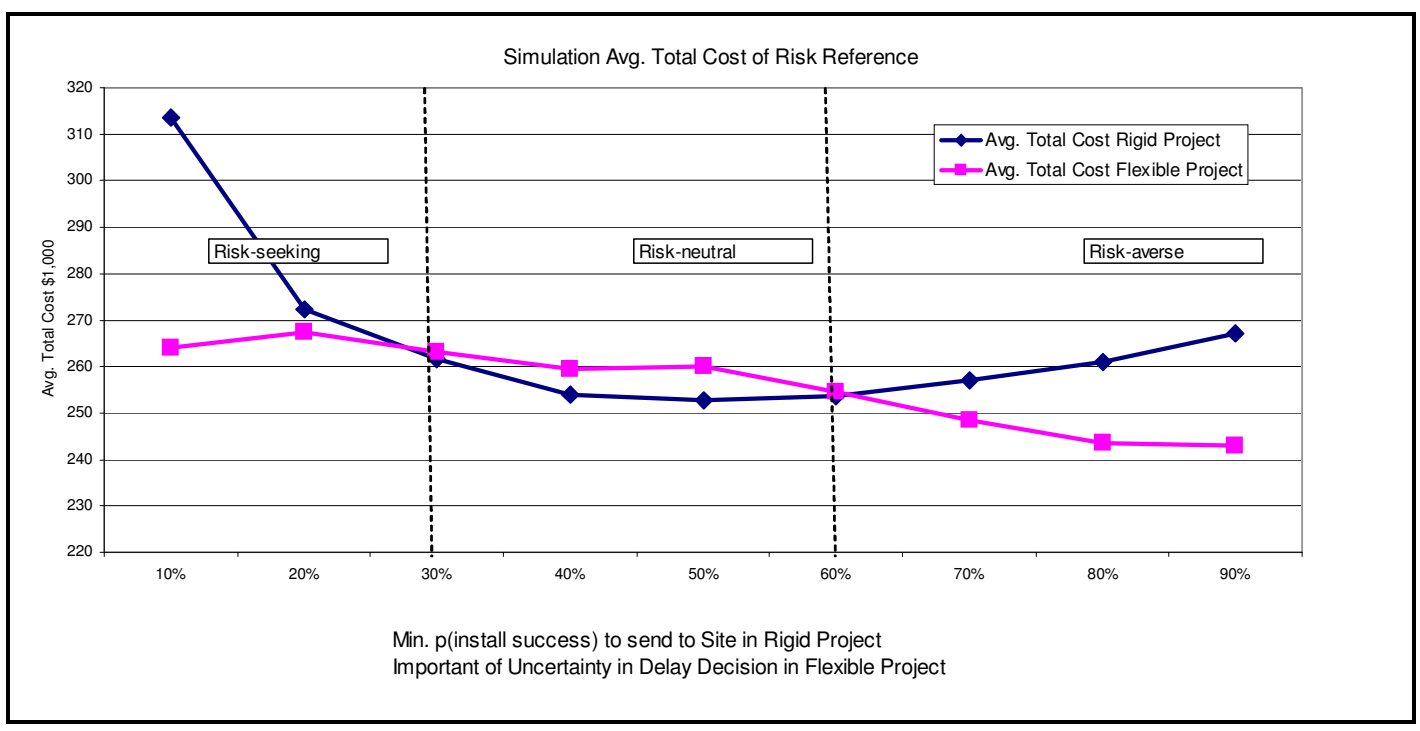

Figure 1: Robustness of flexible policies to risk preference (Wu and Ford 2005)

5. Student understanding of the simulation structure will greatly impact what and how students learn. This is not to suggest that any given depth of understanding is good or bad, better or worse, only that it influences learning significantly. Student understanding can be described with two measures: the transparency of the underlying simulation structure that is made available to students and student understanding of the simulation structure that is made available. Model structure transparency has been described with the terms "black box", "cloudy box", and "glass box". "Black box" models keep the structure of the model that generates behavior hidden from users. "Glass box" models are transparent in that the structure that drives behavior is visible and reasonably understandable to model users. The structures of "cloudy box" models are partially visible, such as by providing a conceptual model structure but not providing formalizations of that conceptual structure. Figure 2 below shows an example of a diagram of a glass-box model. All the essential and essentially all of the model structure is shown in the diagram and the model structure can be described adequately for students (with a background in this type of model) to fully understand the structure. 


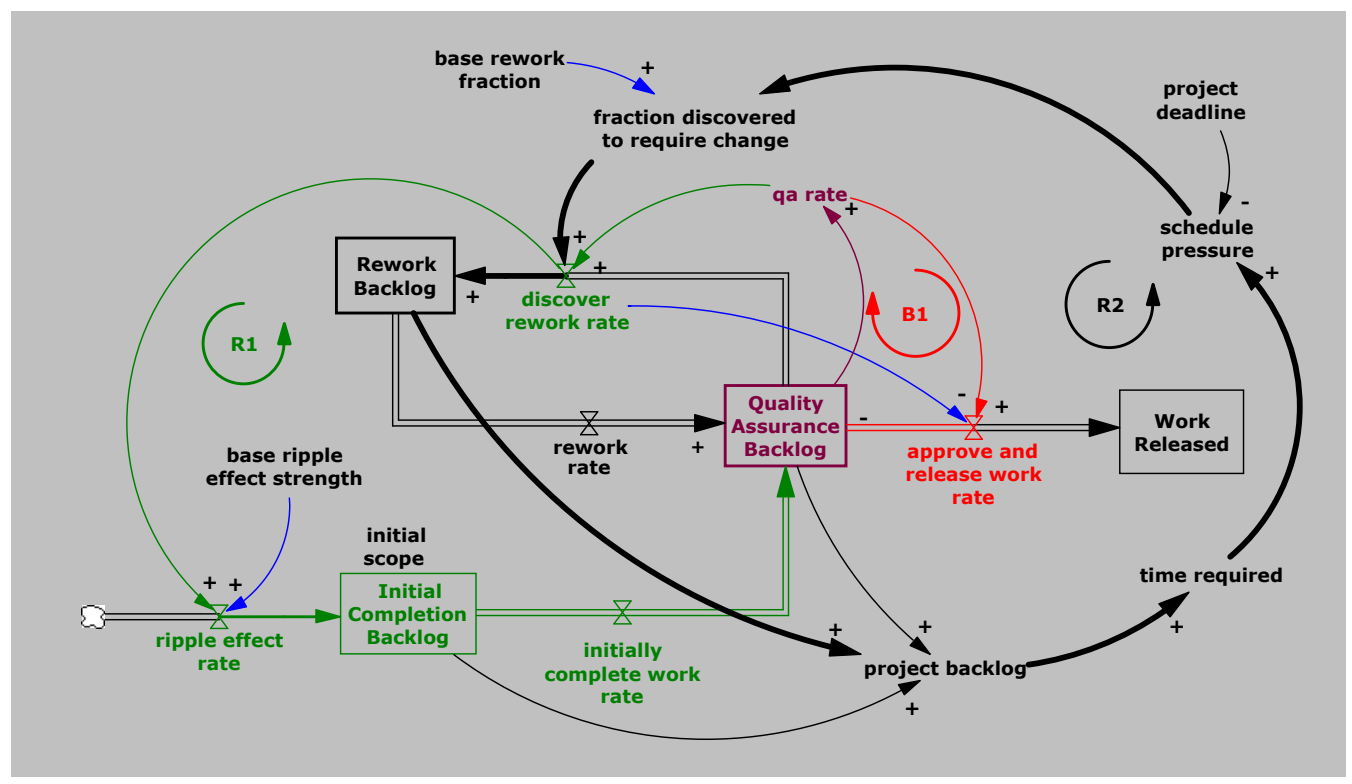

Figure 2: The Tipping Point Model (Taylor, Ford (2006,2008), an Example of a "Glass Box" model

Cloudy box models have been used for teaching with the Project Management Game and the Project Process Design model. Student understanding of the simulation structure that is made available is largely dependent on the background work done by the students and the time devoted in class to explaining the model.

\section{BENEFITS OF INTEGRATING SIMULATION INTO CEM RESEARCH AND TEACHING}

Potential research benefits of integrating simulation into CEM research and teaching include that simulations for teaching can be good foundations for simulations for research (e.g. Rig Installation Challenge), educational settings can facilitate data gathering for research (especially human decision-making research), teaching provides a method to distribute research results, a focus on information and interface required to make a simulator work for teaching may improve the research simulator and thereby research, teaching generates ideas for research (from development and use of the models and from students), and teaching using simulation-based research can attract students into research.

Potential teaching benefits of integrating simulation into CEM research and teaching include that simulators for research can be good foundations for simulators for teaching (e.g. Contingency Management), exercising simulators deeply engages students in their learning by putting them in more realistic circumstances than lecture, homework, etc., research results provide deep understanding that can facilitate teaching and the use of the simulation in teaching (especially at the graduate level), and that research for simulation development can generate descriptions of practitioner problems for use in teaching.

\section{EVALUATION}

Largely through trial and error the author has learned some of what works well and less well for his particular style and circumstances in integrating simulation into CEM research and teaching. Certainly not all of the suggested actions work well or not in all circumstances and careful selection and customization is required. Things that have worked well include: providing students with very specific and detailed instructions about simulation use, demonstrating the use of simulators in class, preparatory assignments followed by in-class use of simulators, tabletop versions of simulators that are used to develop a teaching simulator before a computer simulation is developed, using tabletop simulators in-class for deep student 
involvement, realistic CEM settings, keeping lessons simple for teaching, leading facilitated discussions that lead students to see lessons from their own experience with simulators and link simulator experiences to practice, having students build simulation models and simulate their own behavior, teaching basic theory before simulation experience and subsequently using that theory to explain the experienced behavior, students simulating in teams with individual students taking specific roles, simulating multiple settings/projects/policy, multiple teaching uses of same simulator, and specifying learning objectives.

Things that have not worked well include: simulation models that teach more than one concept at a time (e.g. Project Management Game, first table-top), simulators that are not either a) "bulletproof" (e.g. Project Management Game (web), b) demonstrated (e.g. Rig Installation Challenge, Ciudad Real version), or c) given absolution for their imperfections (e.g. Project Management Game, stand-alone software), simulator settings that are too specific because novice users get confused and experienced users find all the small reasons why the simulator is wrong and decide it is not useful a priori.

\section{CHALLENGES AND ISSUES IN INTEGRATING SIMULATION INTO CEM RESEARCH AND TEACHING}

From the research perspective integrating simulation into CEM research and teaching presents several challenges. One of them is that sometimes the research model has to be more complex than the teaching model to be realistic enough to generate new knowledge. For example, the figure below shows a conceptual structure of the Rig Installation Challenge as used for teaching.



Figure 3: The Rig Installation Challenge Model for Teaching

This is sufficient for effective teaching about basic risk management and other related topics. In contrast, the figure below shows the conceptual structure of the Rig Installation Challenge as altered for research.



Figure 4: The Rig Installation Challenge Model for Researching Real Options 
The expanded (and more complex) simulator was required to adequately model managerial real options.

A second challenge for research in integrating simulation into CEM research and teaching is preventing the "video game" syndrome with computer simulations that can make student behavior and decisionmaking very different from practitioner behavior and decision-making. This is caused by having no performance cost for poor decisions (so just try again!), no time cost for poor decisions (causes fast "throw away" iteration), and little or no decision planning or forethought. Other challenges include how to extend research beyond human decision-making in a teaching environment and IRB permission for human subject experiments. Integrating simulation into CEM research and teaching also presents several other challenges from the teaching perspective. These include model transition from research to teaching is often not trivial, finding an effective balance between realism and simplicity for learning, framing for teaching (the cover story), developing supporting material (instructions, examples, assignments, etc.), student operation error that can destroy results and learning, the potential for non-robust teaching experiences that do not support teaching lessons, instructor practice is often required to get comfortable, difficulties transferring tools to others, student orientation that can take time, and intellectual property issues.

\section{CLOSING}

Opportunities for improvement abound. Three are offered here. First, the case study method can be used more and better in combination with simulations of actual projects. This effort could utilize joint industry/instructor case and simulator development, could integrate cases with existing (project management) simulations, and use practitioner participation in case teaching (especially from the case study project itself). Second, a library of simulations and teaching teams can be developed that facilitates the building of faculty/practitioner/student teams for research and teaching and includes evaluation and involvement with industry. Third, more academically rigorous simulators can be built to train practitioners (vs. traditional students) that are more realistic, have more complexity, and are potentially more valuable for research.

Simulated reality can be very effective for researching and teaching construction engineering and management. By combining table-top and computer simulations researcher/teachers can leverage integrated research and learning simulators to deepen the understanding of CEM challenges and student lessons, expand lessons to adjacent topics, and develop analysis and modeling skills. However, development requires project management experience, teaching experience, and significant time and resources. There are significant potential advantages to integrating simulation into CEM research and teaching. But with them come significant challenges to overcome for success. They can be the basis for valuable discussions for improvement in integration simulation into construction engineering research and teaching.

\section{REFERENCES}

Anderson, E.G. and G.G. Parker. 2002. "The Effect of Learning on the Make/Buy Decision" Production and Operations Management, Vol. 11, No. 3 (2002)

Ford, D., "Achieving Multiple Project Objectives through Contingency Management," 2002. ASCE Journal of Construction Engineering and Management, Vol. 128, No. 1, pp. 30-39, February,.

Ford, D.N., J.M. Lyneis, and TR. Taylor. 2007. "Project Controls to Minimize Cost and Schedule Overruns: A Model, Research Agenda, and Initial Results". 2007 International System Dynamics Conference, Boston, Ma. July 23-27, 2007.

Ford, D. and D. McCormack. 2000. "Effects of Time Scale Focus on System Understanding in Decision Support Systems," Simulation and Gaming, An Interdisciplinary Journal of Theory, Practice, and Research. Vol. 31, No. 3, pp. 309-330, Sept., 2000.

Ford, D. and J. Sterman,.2003. "The Liar's Club: Impacts of Concealment in Concurrent Development Projects," Concurrent Engineering Research and Applications. Vol. 111, No. 3, pp. 211-219, Sept., 2003. 
Ford, D. and J. Sterman. 2003. "Overcoming the 90\% Syndrome: Iteration Management in Concurrent Development Projects," Concurrent Engineering Research and Applications. Vol. 111, No. 3, pp. 177-186, Sept., 2003.

Ford, D. and J. Sterman. 1998. "Modeling Dynamic Development Processes," System Dynamics Review, Vol. 14, No. 1, pp. 31-68, Spring, 1998

Goodman, M. 1974. Study notes in System Dynamics. The MIT Press. Cambridge, MA.

Joglekar, N. and D. Ford. 2005. "Product Development Resource Allocation with Foresight," European Journal of Operational Research. Vol. 160, No. 1, pp.72-87. Jan., 2005.

Lee, Z, D. Ford, and N. Joglekar. 2007. "Resource Allocation Policy Design for Reduced Project Duration: A Systems Modeling Approach," Systems Research and Behavioral Science. Vol. 24, No. 6, pp. 551 to 566. Nov-Dec 2007.

Sterman, J.D. 2000. Business Dynamics, Systems Thinking and Modeling for a Complex World. McGraw Hill. New York. 2000.

Taylor, T and D. Ford. 2006. "Tipping Point Dynamics in Development Projects" System Dynamics Review. Vol. 22, No. 1. pp. 51-71. spring, 2006.

Taylor, TR and DN Ford. 2008. "Managing Tipping Point Dynamics in Development Projects". ASCE Journal of Construction Engineering and Management. Vol. 134, No. 6, pp. 421-431. June, 2008.

Tommelein, I.D. 1998. "Pull-Driven Scheduling for Pipe-Spool Installation: Simulation of Lean Construction Technique. ASCE J Construction Engineering and Management. 124(4): 279-288.

Wu, Y. and D. Ford. 2005. "Managerial Real Options Practice in Large System Acquisition: Empirical Descriptions and Comparison with Theory" 2nd Annual Acquisition Research Symposium. Naval Postgraduate School. Monterey, CA. May 18-19, 2005.

\section{AUTHOR BIOGRAPHY}

DAVID FORD is an Associate Professor of Construction Engineering and Management in the Zachry Department of Civil Engineering at Texas A\&M and a Research Associate Professor of Acquisition in the Graduate School of Business and Public Policy at the US Naval Postgraduate School, Monterey, Ca. He has also held a faculty position at the University of Bergen, Norway. Dr. Ford received his doctorate from MIT in Dynamic Engineering Systems. His current research interests include the sustainability of engineered systems, the use of real options for risk management and policy implementation, tipping point dynamics, project management and control, and the management of professional services firms. Dr. Ford's research work has been published in several academic journals, including IEEE Transactions on Engineering Management, European Journal of Operations Research, System Dynamics Review, Construction Management and Economics, ASCE Journal of Construction Engineering and Management, ASCE Journal of Management in Engineering, and Engineering Construction and Architectural Management. He currently serves as a Managing Editor of the System Dynamics Review. His email address is: <davidfordetamu.edu>. 